\title{
Desa Adat Timbul: Kampung Wisata Berbasis Pertanian dan Edukasi
}

\author{
I Made Candra Wahyudi Putra ${ }^{1 *}$, I Gede Adi Sanjaya ${ }^{2}$, Dewa Ayu Sintya Dewi ${ }^{3}$, Ni \\ Kadek Anggi Pratiwi ${ }^{4}$, I Gede Astawan 5 (D) \\ 1,2,3,4,5 Universitas Pendidikan Ganesha, Singaraja, Indonesia \\ *Corresponding author: Candrawahyudi251@gmail.com
}

\begin{abstract}
Abstrak
Desa Adat Timbul, Tegallalang merupakan salah satu desa yang terletak di wilayah Kecamatan Tegallalang, Kabupaten Gianyar. Potensi alam desa ini sangatlah melimpah seperti letak sawah yang strategis, memiliki air terjun, dan banyak unit usaha yang bisa dikembangkan menjadi objek wisata berbasis edukasi. Namun potensi wisata desa masih mengalami kendala dalam marketing. Berangkat dari masalah tersebut tim PHP2D BEM FIP Universitas Pendidikan Ganesha Berinisiatif untuk membantu Desa Adat Timbul mengembangkan dan membantu di bidang marketing untuk mempromosikan desa ini menjadi Kampung Wisata berbasis Pertanian dan Edukasi. Kegiatan dilaksanakan selama 6 Bulan meliputi Pelembagaan Unit Usaha di bidang pariwisata, Penataan areal sawah dan perancangan publikasi Media Sosial. Hasilnya Desa Adat Timbul yang memiliki beragam potensi wisata, meliputi areal persawahan yang strategis, yang diikuti dengan unit-unit usaha yang dikelola secara mandiri oleh masyarakat telah dikembangkan bersama oleh Desa Adat Timbul. Harapanya warga bisa tetap menjaga dan mengelola wisata dengan baik serta bisa lebih menggali potensi wisata yang sudah ada maupun yang belum untuk lebih dikembangkan.
\end{abstract}

Kata Kunci: Desa Adat Timbul, Kampung Wisata, Pertanian dan Edukasi

\section{Abstract}

Timbul Traditional Village, Tegallalang is one of the villages located in the Tegallalang District, Gianyar Regency. The natural potential of this village is very abundant such as the strategic location of rice fields, has a waterfall, and many business units that can be developed into education-based tourism objects that are still experiencing problems in marketing. The PHP2D BEM FIP Team of Ganesha University of Education took the initiative to help Timbul Traditional Village develop and assist in marketing to promote this village into an Agriculture and Education-based Tourism Village. Activities carried out for 6 months include Institutionalization of Business Units in the tourism sector, Structuring rice fields and designing Social Media publications. The result is Timbul Traditional Village which has a variety of tourism potential, including strategic rice fields, followed by business units which managed independently by the community, that have been jointly developed by the Timbul Traditional Village. It is hoped that residents can maintain and manage tourism well and can further explore existing and undeveloped tourism potentials.

Keywords: Timbul Traditional Village, Tourism Village, Agriculture and Education

\section{PENDAHULUAN}

Pariwisata diistilahkan sebagai agen perubahan budaya (agen of cultural change) yang mempengaruhi perjalanan orang, adat istiadat, upacara keagamaan serta cara berpikir masyarakat (Andry, 2018; Santi et al., 2020; Subawa, 2018; Syafrini et al., 2016; Yoeti et al., 2006). Saat ini pariwisata merupakan salah satu sektor yang menghasilkan devisa tinggi bagi negara. Sektor pariwisata merupakan bidang kehidupan yang kian berkembang pesat dan menjadi salah satu mata pencarian utama masyarakat Bali. Bali yang kita kenal merupakan icon pariwisata Indonesia yang telah diakui dunia. Wisatawan tentunya tidak asing dengan Kuta, Seminyak, dan Ubud yang banyak menawarkan pengalaman baru pada saat berkunjung ke Bali.

$\begin{array}{ll}\text { History: } & \\ \text { Received } & \text { : September 09, } 2021 \\ \text { Revised } & \text { : September 12, } 2021 \\ \text { Accepted } & \text { : November 12, } 2021 \\ \text { Published } & \text { : November 25, 2021 }\end{array}$


Seiring dengan berkembangnya pariwisata di Bali, banyak tempat wisata tersebut menjadi terlalu penuh dengan kebisingan. Justru sekarang ini sulit untuk menjumpai wisata yang menawarkan destinasi baru yang bisa menawarkan tempat wisata yang menawarkan ketenangan, kesujukan yang syarat akan kebudayaan Bali. Selain itu terdapat masalah lain yang diakibatkan oleh terjadinya pandemi Covid-19, penurunan angka kunjungan wisatawan asing juga menjadi maslah baru yang kini melanda sektor Pariwisata di Bali (Maharani \& Mahalika, 2020; Paramita \& Putra, 2020; Purwahita et al., 2021; Sumarni, 2020; Suprihatin, 2020). Diperkiran lebih dari USD 1,3 miliar devisa negara berkurang, dikarenakan terhambatnya sektor pariwisata. Hal ini juga disebabkan karena sebagian besar wisatawan yang masuk ke Bali berasal dari negara Tiongkok (Anggarini, 2021). Meski menjadi tantangan yang berat, hal ini tidak mempengaruhi semangat masyarakat untuk kembali membangun sekotor pariwisata, hal ini ditandai dengan mulai banyaknya perisiapan pelaku pariwisata dalam menyambut wisatawan mancanegara yang wacanananya bisa berkunjung ke Bali pada tanggal 14 Oktober 2021. Maka dari itu BEM FIP Undiksha memiliki ide untuk mulai merancang kampung wisata berbasis pertanian dan edukasi. Program yang dilaksanakan di Desa Adat Timbul, Desa Pupuan, Kecamatan Tegallalang, Kabupaten Gianyar. Tempat ini dipilih karena memiliki potensi wisata yang bagus namun belum terkelola dengan baik.

Dengan menawarkan destinasi wisata yang mengandalkan kearifan lokal yang dimiliki desa ini, seperti Terasering Sawah, Pengalaman Berkuda, Glamping, Retreat, Edukasi, Tracking, Cycling, serta kegiatan kebudayaan yang diharapkan bisa menarik minat wisatawan untuk kembali berkunjung ke Bali, khususnya Kampung Wisata Timbul. Wisata minat khusus, dalam hal ini desa wisata, mengarah pada daya tarik budaya lokal yang menjadi tren wisata pada jaman moderen seperti paradoks global dimana semakin besar pengaruh globalisasi, semakin tinggi keinginan untuk menekuni lokalisasi, khususnya seni tradisional (Ariani, 2011; Prakoso, 2015; Prasta, 2021; Putra, 2020; Sulistiyani et al., 2021). Oleh sebab itu pengelolaan sumber daya perdesaan selayaknya memperhatikan pengintegrasian perspektif ekonomi dan ekologi, memperkuat dinamika ekonomi sosial lokal, dan memahami potensi sumberdaya perdesaan (Baiquni, 2006; Febriana \& Mardiana, 2019; Irfan, 2021) Dengan adanya unit-unit usaha yang sudah dibentuk secara suadaya oleh masyarakat dan kini akan dikelola di bidang marketing oleh pihak Desa Adat Timbul akan membuat unit usaha tersebut lebih terkelola dan sistematis dan menghindari persaingan dagang antar warga masyarakat.

Tujuan utama dari perintisan kampung wisata ini untuk meningkatkan pendapatan masyarakat, serta memulai pergerakan baru di masa Pandemi Covid-19. Pemanfaatan potensi ekonomi, sosial dan budaya masyarakat lokal secara optimal merupakan alasan rasional dalam pengembangan pariwisata pedesaan (Damanik, 2013; Khasanah, 2019; Yatmaja, 2019). Sehingga dengan demikian kegiatan PHP2D ini diharapkan dapat menunjang upaya pemerintah dalam mendatangkan wisatawan mancanegara untuk kembali menstabilkan sektor ekonomi yang mati suri selama masa pandemi. Proses pembentukan kepuasan wisatawan terdiri dari berbagai faktor seperti: produk wisata, instrumen evaluasi, dan hasil dari yang mereka terima (produk dan jasa) (Djunaedi et al., 2022; Ernawati et al., 2018; Syafitri et al., 2019). Secara eksplisit sumberdaya alam berupa tanah, mineral, air, batuan, relief, bahan bakar. Potensi di suatu wilayah akan bermanfaat apabila dapat dikelola oleh manusia (Al Hamid \& Fehrezy, 2021; Rahmi et al., 2020; Suparmoko, 1994). UU No. 10 Tahun 2009 pariwisata adalah industri yang menghimpun kumpulan usaha pariwisata yang saling terkait dalam rangka menghasilkan barang dan/atau jasa bagi pemenuh kebutuhan wisatawan dalam penyelenggaraan pariwisata. Dengan demikian industri pariwisata dapat diartikan sebagai sekumpulan atau himpunan usaha yang menghasilkan berbagai jasa maupun barang yang dibutuhkan oleh mereka yang melakukan kunjungan wisata atau pariwisata. 


\section{METODE}

Kegiatan pengabdian dilaksanakan di Desa Adat Timbul, Desa Pupuan, Kecamatan Tegallalang, Kabupaten Gianyar. Kegiatan ini melibatkan kepala desa, pihak pengelola kampung wisata, BUPDA (Baga Usaha Padruen Desa Adat), kelian adat, dan masyarakat setempat. Dalam penelitian ini peneliti menggunakan metode deskriptif kualitatif yang bertujuan agar mampu memperoleh gambaran dan memahami situasi di lapangan sebagaimana adanya tanpa dimanipulasi sedikitpun terhadap sasaran penelitian (Sari, 2012). Pengumpulan data pada penelitian ini membutuhkan data primer dan juga data sekunder. Data primer diperoleh dengan cara melakukan wawancara dan observasi dengan pihak-pihak yang terkait dan dokumentasi kegiatan yang dilaksanakan selama dilapangan. Sedangkan data sekunder diperoleh dengan mengumpulkan dokumen-dokumen desa, dokumen yang menyangkut terkait kampung wisata, dan dokumen potensi desa (Yani, 2021). Bentuk monitoring dan evaluasi yang dilaksanakan secara langsung di lapangan. Tim BEM FIP Undiksha menginap sementara waktu merupakan bentuk implementasi dari upaya monitoring dan evaluasi yang di laksanakan tim BEM FIP Undiksha.

\section{HASIL DAN PEMBAHASAN}

Desa Adat Timbul merupakan salah satu desa yang memiliki potensi dalam pengembangan kampung wisata, khususnya dalam bidang pertanian dan edukasi. Kekurangan dari pengembangan kampung wisata ini adalah salah pengelolaan serta terbatasnya manajemen dan sumber daya manusia. Adapun hal-hal yang sudah dilaksanakan sesui metode oleh tim PHP2D bersama masyarakat Desa Adat Timbul dalam pengembangan kampung wisata diantaranya sebagai berikut. Tahap pertama adalah tahap perencanaan. Dalam perencanaan wisata berbasis pertanian dan edukasi mendapatkan hasil bahwa, masyarakat sudah memiliki unit-unit usaha yang mendukung pengembangan kampung wisata yang bergerak dalam bidang pertanian dan edukasi. Maka dari itu, yang diperlukan hanya pengelolaan lebih lanjut kepada unit-unit usaha masyarakat yang sudah ada dan gencar dalam promosinya. 2). Observasi Unit-unit Usaha yang Dimiliki Masyarakat. Observasi dilakukan kepada unit-unit usaha yang menjadi elemen-elemen dalam pengembangan kampung wisata. Unit-unit usaha tersebut meliputi glamping, retreat camp, terasering sawah, pengalaman berkuda, tracking, dan arang bambu. 3). Pelaksanaan Program. Pelaksanaan program dalam pengembangan kampung wisata yaitu pengelolaan marketing Kampung Wisata pada Website dan sosial media Lebih lanjut, pengetahuan mengenai wisatawan sangat diperlukan dalam merencanakan produk wisata yang sesuai dengan keinginan kelompok pasar tertentu, termasuk merencanakan strategi pemasaran yang tepat bagi kelompok pasar tersebut. Salah satunya mendongkrak strategi marketing dalam mempromosikan Kampung Wisata Timbul melalui website dan sosial media lainnya yang sudah berjalan dan dikembangkan.

Beberapa hasil dari pelaksanaan program pengabdian adalah sudah terkelolanya beberapa objek wisata dan lembaga pengurus seperti diantaranya, 1.) Lobby Kampung, Wisata Desa Adat Timbul di desain dengan berbaur dengan alam. 2.) Bali Natural Healing, merupakan salah satu destinasi wisata yang mengangkat konsep healing atau penyembuhan. Dengan konsep tersebut maka di dalamnya ditawarkan paket meditasi atau yoga penyembuhan di dalam gua dekat dengan air terjun. 3.) Arang Bambu, merupakan salah satu unit usaha yang berada di Desa Adat Timbul dan sudah mendapat pengakuan secara nasional. Tempat ini menawarkan paket kunjungan dan juga paket experience pembakaran arang bamboo tersebut diolah menjadi bahan-bahan kosmetik. 4.) Jalur Tracking, dibuat untuk memberikan wisatawan pengalaman dalam menjelajahi areal persawahan dan edukasi dalam pengelolaan sawah secara tradisional. 5.) Subak Gallery, merupakan salah satu program kerja pengadaan barang dari Tim PHP2D yang memajang alat-alat pertanian tradisional beserta 
deskripsinya. 6.) Mud Area, dirancang oleh Tim PHP2D sebagai sarana perkenalan permainan tradisional (Seni dan budaya). 7.) Ubud Retreatcamp, merupakan salah satu unit usaha swadaya milik kelompok masyarakat. Destinasi ini menawarkan penginapan yang nyaman untuk wisatawa yang berada di areal persawahan dan menambah nuansa alami dan sangat tepat untuk menenangkan diri. 8.) Homestay, adalah salah satu unit yang dikelola dan bagian dari paket kampung wisata adalah penginapan atau homestay, agar memudahkan wisatawan untuk tinggal sejenak di desa wisata. 9.) Selain itu juga dibentuk lembaga pengurus, yaitu BUPDA (Baga Utsaha Padruwen Desa Adat) yang membantu menaungi desa Adat Timbul menjadi Kampung Wisata dan pengelola desa wisata secara khusus agar grafis target kunjungan wisatawan tetap merangkak naik. 10.) Dan yang terakhir adalah warung prapen. Warung prapen hadir dengan suasana pedesaan yang dikelilingi oleh banyak pepohonan hijau. Tak hanya itu, adanya hiasan bamboo dengan bebatuan di sekitarnya membuat nuansa alamnya terasa kental.

Dengan menawarkan destinasi wisata yang mengandalkan kearifan lokal yang dimiliki desa ini, seperti Terasering Sawah, Pengalaman Berkuda, Glamping, Retreat, Edukasi, Tracking, Cycling, serta kegiatan kebudayaan yang diharapkan bisa menarik minat wisatawan untuk kembali berkunjung ke Bali, khususnya Kampung Wisata Timbul. Wisata minat khusus, dalam hal ini desa wisata, mengarah pada daya tarik budaya lokal yang menjadi tren wisata pada jaman moderen seperti paradoks global dimana semakin besar pengaruh globalisasi, semakin tinggi keinginan untuk menekuni lokalisasi, khususnya seni tradisional (Ariani, 2011; Prakoso, 2015; Prasta, 2021; Putra, 2020; Sulistiyani et al., 2021). Oleh sebab itu pengelolaan sumber daya perdesaan selayaknya memperhatikan pengintegrasian perspektif ekonomi dan ekologi, memperkuat dinamika ekonomi sosial lokal, dan memahami potensi sumberdaya perdesaan (Baiquni, 2006; Febriana \& Mardiana, 2019; Irfan, 2021) Dengan adanya unit-unit usaha yang sudah dibentuk secara suadaya oleh masyarakat dan kini akan dikelola di bidang marketing oleh pihak Desa Adat Timbul akan membuat unit usaha tersebut lebih terkelola dan sistematis dan menghindari persaingan dagang antar warga masyarakat.

\section{SIMPULAN DAN SARAN}

Desa Adat Timbul, Tegallalang merupakan salah satu desa yang terletak di wilayah Kecamatan Tegallalang, Kabupaten Gianyar. Potensi alam desa ini sangatlah melimpah seperti letak sawah yang strategis, memiliki sumber daya alam yang melipah dan bisa dimanfaatkan dan banyak unit usaha yang bisa dikembangkan menjadi obyek wisata berbasis edukasi yang masih mengalami kendala dalam marketing. Tim PHP2D BEM FIP Universitas Pendidikan Ganesha berpartisipasi bersama Pengurus Desa yaitu BUPDA untuk mengembangkan dan membantu permasalahan yang ada di Desa Adat Timbul yaitu di bidang marketing untuk mempromosikan desa ini menjadi Kampung Wisata berbasis Pertanian dan Edukasi. Banyak Unit- unit usaha masyarakat yang sudah dibentuk dan sudah dikelola. Unitunit usaha yang sudah dikelola kita naungi menjadi Kampung Wisata Desa Adat Timbul berlandaskan Sapta pesona tersebut meliputi aman, tertib, bersih, sejuk, indah, ramah, dan kenangan. Bagi masyarakat sendiri sadar wisata ini memiliki prospek yang baik, yaitu lapangan pekerjaan dan peluang pendapatan yang meningkat. Dari masyarakat perlu memahami konsep dari sadar wisata dalam hal ini digambarkan sebagai bentuk kesadaran masyarakat untuk berperan aktif. Dimana masyarakat menyadari peran dan tanggung jawab sebagai tuan rumah yang baik bagi wisatawan yang berkunjung untuk mewujudkan lingkungan dan suasana yang kondusif. Diharapkan masayarakat Desa Adat Timbul mmpu mempromosikan di sosial media maupun di WEB yang sudah dibentuk serta dapat melanjutkan mengelola kampung wisata Desa Adat Timbul dengan baik. 


\section{DAFTAR RUJUKAN}

Al Hamid, R., \& Fehrezy, A. F. (2021). Pendampingan Potensi Ekonomi Masyarakat Desa Kembang, Kabupaten Pacitan. Journal of Social Empowerment, 6(2), 85-92. https://ejournal.stkippacitan.ac.id/index.php/jse/article/view/369.

Andry, A. (2018). Peran Agen Perubahan Pada Masyarakat Tradisional Untuk Diversifikasi Produk Mandau Sebagai Bentuk Perubahan Sosial. Jurnal Rekarupa, 4(1). http://ejurnal.itenas.ac.id/index.php/rekarupa/article/view/1464.

Anggarini, D. T. (2021). Upaya pemulihan industri pariwisata dalam situasi pandemi Covid19. Jurnal Pariwisata, $8(1), \quad 22-31$. https://scholar.archive.org/work/m6uyf76v7verfgo4uqals2pkpq/access/wayback/https: //ejournal.bsi.ac.id/ejurnal/index.php/jp/article/download/9809/pdf.

Ariani, N. M. (2011). Pergulatan Otentisitas dan Komodifikasi dalam Pariwisata Budaya. Jurnal Analisis Pariwisata, 11(1), 27-40.

Baiquni. (2006). Pengelolaan sumberdaya perdesaan dan strategi penghidupan rumahtangga di Provinsi Daerah Istimewa Yogyakarta pada masa krisis 1998-2003. Universitas Gadjah Mada.

Damanik, J. (2013). Pariwisata Indonesia Antara Peluang dan Tantangan. Pustaka Pelajar.

Djunaedi, D., Basrie, F. H., Lidiawan, A. R., \& Vitasmoro, P. (2022). Dampak Citra Destinasi, Faktor CRM dan Kepuasan Wisatawan Terhadap Loyalitas Wisatawan Gunung Kelud pada Era New Normal. At-Tadbir: Jurnal Ilmiah Manajemen, 6(1), 26-40. https://ojs.uniska-bjm.ac.id/index.php/jurnalattadbir/article/view/5801.

Ernawati, H., Avenzora, R., \& Damiasih, D. (2018). Kepuasan Wisatawan Terhadap Situs Warisan Budaya Candi Prambanan. Jurnal Ecodemica Jurnal Ekonomi Manajemen Dan Bisnis, $2(2)$. https://ejournal.bsi.ac.id/ejurnal/index.php/ecodemica/article/view/4493.

Febriana, H., \& Mardiana, R. (2019). Hubungan Partisipasi Masyarakat Dengan Keberlanjutan Ekologi, Sosial-Budaya, Dan Ekonomi Dalam Ekowisata Desa Adat. Jurnal Sains Komunikasi Dan Pengembangan Masyarakat [JSKPM], 3(2). http://ejournal.skpm.ipb.ac.id/index.php/jskpm/article/view/81.

Irfan, M. (2021). Strategi Membangun Desa Mandiri Ekonomi kereatif Berbasis Potensi Lokal (Di Desa Risa Kecamatan Woha Kabupaten Bima. PANRITA: Journal of Science, Technology, and Arts, l(1). https://www.journal.dedikasi.org/pjsta/article/view/13.

Khasanah, D. U. (2019). Pola Kemitraan Pemerintah Daerah Dengan Kelompok Sadar Wisata Pandawa Dieng Kulon Dalam Pengembangan Pariwisata. Journal of Politic and Government Studies, 8(4), 341-350. https://ejournal3.undip.ac.id/index.php/jpgs/article/download/25063/22315.

Maharani, A., \& Mahalika, F. (2020). New Normal Tourism Sebagai Pendukung Ketahanan Ekonomi Nasional Pada Masa Pandemi. Jurnal Kajian Lemhannas RI, 8(2). http://jurnal.lemhannas.go.id/index.php/jkl/article/view/87.

Paramita, I. B. G., \& Putra, I. G. G. P. A. (2020). New Normal Bagi Pariwisata Bali Di Masa Pandemi Covid 19. Pariwisata Budaya: Jurnal Ilmiah Agama Dan Budaya, 5(2), 5765. http://ejournal.ihdn.ac.id/index.php/PB/article/view/1723.

Prakoso, A. A. (2015). Pengembangan Wisata Pedesaan Berbasis Budaya Yang Berkelanjutan Di Desa Wisata Srowolan Sleman. Jurnal Kepariwisataan, 9(2), 6176.

https://www.academia.edu/download/55862227/1._Pengembangan_Wisata_Pedesaaa n_Berbasis_Budaya.pdf.

Prasta, M. (2021). Pariwisata Berbasis Masyarakat Sebagai Pelestari Tradisi Di Desa Samiran. Jurnal Kepariwisataan: Destinasi, Hospitalitas Dan Perjalanan, 5(1), 99- 
109. https://journal.stp-bandung.ac.id/index.php/jk/article/view/379.

Purwahita, A. R. M., Wardhana, P. B. W., Ardiasa, I. K., \& Winia, I. M. (2021). Dampak Covid-19 terhadap Pariwisata Bali Ditinjau dari Sektor Sosial, Ekonomi, dan Lingkungan (Sebuah Tinjauan Pustaka). Jurnal Kajian Dan Terapan Pariwisata, 1(2), 68-80. http://jurnal.akpar-denpasar.ac.id/index.php/diparojs/article/view/29.

Putra, D. P. B. P. (2020). Pengembangan Desa Wisata Carangsari Dan Partisipasi Masyarakat Lokal. Jurnal Masyarakat Dan Budaya, 22(2), 1-15. https://jmb.lipi.go.id/jmb/article/view/838.

Rahmi, V. A., Fathoni, M. Z., \& Ismanto, H. (2020). Potensi Lokal Pengembangan Bisnis Desa Saat Pandemi Tengah Melanda Negeri. MATRIK: Jurnal Manajemen Dan Teknik Industri-Produksi, 21(1), 53-62. http://journal.umg.ac.id/index.php/matriks/article/view/1614.

Santi, F. U., Asih, K. Y., Sari, D. A., \& Pristanti, D. (2020). Pemetaan Kebutuhan Program Parenting Education dalam Persiapan Regenerasi Remaja di Desa Wisata Pentingsari Yogyakarta. Diklus: Jurnal Pendidikan Luar Sekolah, 4(2), 124-134. https://journal.uny.ac.id/index.php/jurnaldiklus/article/view/32265.

Sari, W. Q. (2012). Pelaksanaan inklusi di sekolah dasar negeri 14 Pakan Sinayan Payakumbuh. Jurnal Ilmiah Pendidikan Khusus, I(1), 190-197. http://ejournal.unp.ac.id/index.php/jupekhu.

Subawa, I. M. P. (2018). Bali dalam Dinamika Masyarakat dan Kebudayaan di Tengah Perkembangan Pariwisata. Pariwisata Budaya: Jurnal Ilmiah Agama Dan Budaya, 3(1), 95-109. http://www.ejournal.ihdn.ac.id/index.php/PB/article/view/428.

Sulistiyani, E., Poerbo, S., Suwardi, S., Karnowahadi, K., \& Aryono, S. (2021). MODEL Pengembangan Desa Kreatif Berkarakter Budaya Lokal. Seminar Hasil Penelitian Dan Pengabdian Masyarakat, 3(1). https://jurnal.polines.ac.id/index.php/Sentrikom/article/view/2794.

Sumarni, Y. (2020). Pandemi Covid-19: Tantangan Ekonomi Dan Bisnis. Al-Intaj: Jurnal Ekonomi Dan Perbankan Syariah, 6(2), 46-58. https://ejournal.iainbengkulu.ac.id/index.php/Al-Intaj/article/view/3358.

Suparmoko. (1994). Ekonomi Sumberdaya Alam dan Lingkungan. BPFE.

Suprihatin, W. (2020). Analisis perilaku konsumen wisatawan era pandemi Covid-19 (Studi kasus pariwisata di Nusa Tenggara Barat). Bestari, 1(1), 56-66. https://jurnalbestari.ntbprov.go.id/index.php/bestari1/article/view/9.

Syafitri, E. D., Nugroho, R. A., \& Yorika, R. (2019). Analisis Tingkat Kepuasan Pengunjung Daya Tarik Wisata Kebun Raya Balikpapan. Journal of Indonesian Tourism, Hospitality and Recreation, 4(1), 1-8. https://ejournal.upi.edu/index.php/Jithor/article/view/28205.

Syafrini, D., Susilawati, N., \& Hasmira, M. H. (2016). Partisipasi masyarakat lokal dalam mengembangkan kawasan wisata keluarga. Jurnal Socius, 3(2), 122-139. http://repository.unp.ac.id/17203/1/.pdf.

Yani, A. (2021). Tata Kelola Desa Wisata di Desa Nangamiro Kecamatan Pekat Kabupaten Dompu. Jurnal Penkomi Kajian Pendidikan Dan Ekonomi, 4(2), 115-124. http://jurnal.stkipbima.ac.id/index.php/PK/article/view/551.

Yatmaja, P. T. (2019). Efektivitas Pemberdayaan Masyarakat Oleh Kelompok Sadar Wisata (Pokdarwis) Dalam Mengembangkan Pariwisata Berkelanjutan. Jurnal Ilmiah Administrasi Publik Dan Pembangunan, 10(1), 27-36. https://www.academia.edu/download/60369674/4_.pdf.

Yoeti, H., A., O., \& Dkk. (2006). Pariwisata Budaya: Masalah dan Solusinya. PT. Pradnya Paramita. 